\title{
Uso dos Registos Clínicos Eletrónicos para Investigação: Novos Desafios Éticos e Soluções Possíveis
}

\author{
Use of Electronic Medical Records for Research: New \\ Ethical Challenges and Possible Solutions
}

\begin{abstract}
Carlos MENESES-OLIVEIRA $\triangle 1,2$
Acta Med Port 2019 May;32(5):332-334 - https://doi.org/10.20344/amp.11280

RESUMO

Alguns investigadores entendem que as Comissões de Ética para a Saúde são um bloqueio aos estudos clínicos observacionais. No que toca aos estudos retrospetivos há quem proponha resolver este problema tratando os Dados Pessoais de Saúde como dados administrativos simples na posse do Estado e há quem interprete o novo Regulamento Geral de Proteção de Dados (União Europeia) 2016/679 de forma menos garantista que a Lei $n^{\circ} 21 / 2014$, de 16 de abril (sobre a Investigação Clínica), resultando em ambos os casos na presunção que o silêncio do participante constitui consentimento, mesmo se ninguém tentar sequer informá-lo do novo uso dos seus dados. Estas soluções colidem com garantias éticas de proteção dos direitos dos doentes. Propomos uma alternativa ética a estas propostas.

Palavras-chave: Anonimização de Dados; Comissões de Ética Clínica; Portugal; Registos Electrónicos de Saúde; Registos de Saúde Pessoal

ABSTRACT

Some clinicians feel that Ethics Committees act as a blockade to observational clinical studies. In the case of retrospective studies some have tried to solve this problem by reducing this sensitive data to simple administrative data in the hands of the government. Others see the new European General Data Protection Regulation 2016/679 (European Union) as being more liberal than the Portuguese Law $n^{\circ} 21 / 2014$, April $16^{\text {th }}$ (Clinical Research Law). Both solutions presume participant consent from his / her silence, even if nobody truly tried to specifically inform him / her. Such views do collide with the guarantees of protection of patient's ethical rights. In this article we propose an ethical alternative to those positions.
\end{abstract}

Keywords: Data Anonymization; Electronic Health Records; Ethics Committees, Clinical; Health Records, Personal; Portugal

\section{INTRODUÇÃO}

$O$ doente e o seu médico estabelecem uma aliança terapêutica que facilita a entrega ao clínico dos seus dados pessoais de saúde (DPS). Também é desejável que exista confiança entre o participante em estudo clínico e o investigador, mas, em ambos os casos, se acedidos pela pessoa errada esses DPS podem ameaçar direitos fundamentais.

Desde Nuremberga ${ }^{1}$ que se tentam proteger os participantes, defendendo-se princípios universais, três dos quais estão em crise nos estudos observacionais: A Autonomia, que obriga à autorização do doente, a Confidencialidade dos DPS e o Primado da Pessoa Humana, que estabelece que a pessoa do doente singular é um bem superior ao interesse público da ciência.

Os processos clínicos eletrónicos (PCE) e outros registos digitais, expandiram oportunidades e riscos. A legibilidade e acessibilidade dos PCE adicionaram uma ameaça nova à confiança - a que provém da má guarda dos dados ou da falta de consciência de decisor do seu fiel depositário, nomeadamente no contexto de investigação clínica.

As Comissões de Ética para a Saúde (CES), têm a obrigação de garantir que os DPS são pertença dos titulares, mas, por exemplo ao exigirem consentimento informado (Cl) na maioria dos estudos observacionais, levam alguns investigadores a olhar para as CES como um entrave à investigação. Ora estas não devem ser um bloqueio buro- crático ao avanço da ciência, sem, contudo, abandonarem o principal: a proteção dos participantes e da sua confiança nas instituições. Se claudicarem, promoverão, no curto prazo o incumprimento de investigadores e de instituições e, no médio prazo, opções legislativas que menorizem o papel das CES.

O Regulamento Geral de Proteção de Dados (UE) 2016/679 (RGPD), em vigor desde 25 de maio de 2018, dispersou parte das atribuições da Comissão Nacional de Proteção de Dados (CNPD) o que pode levar a interpretações menos rigorosas da lei.

A Lei $n^{\circ}$ 21/2014, de 16 de abril (sobre a investigação clínica - LIC), definiu o Centro de Estudos Clínicos (CESC) como a entidade que, inserida numa unidade de saúde (ou outra), realiza o estudo clínico, cujo responsável é até informado diretamente do progresso de cada investigação, sem, contudo, Ihe atribuir as competências substantivas necessárias e ignora, entre outras limitações, a especificidade dos estudos em que o Investigador é o médico do participante. Nestes não há diferença ética major entre a autorização para tratamento dos DPS dada pelo doente no âmbito da aliança terapêutica e autorização para tratamento dos mesmos dados pelo mesmo médico em estudo observacional. Apesar de nesta sobreposição de papéis se jogarem interesses distintos, pois na primeira o principal

\footnotetext{
1. Comissão de Ética para a Saúde. Hospital Beatriz Ângelo. Loures. Portugal.

2.. Serviço do Medicina Intensiva. Hospital Beatriz Ângelo. Loures. Portugal.

$\square$ Autor correspondente: Carlos Meneses-Oliveira. cmenesesoliveira@sapo.pt

Recebido: 12 de setembro de 2018 - Aceite: 17 de dezembro de 2018 | Copyright @ Ordem dos Médicos 2019
} 
beneficiário é o doente, que procura o médico, e na segunda é o médico e, eventualmente, a comunidade, é, em geral, menos crível que haja, do lado do doente, oposição ao benefício extraído pelo investigador ou pela comunidade do uso secundário dos seus DPS, se não for ameaçada a sua privacidade.

O autor discute o enquadramento das CES nos CESC, as dificuldades introduzidas pela exigência de $\mathrm{Cl}$ nos estudos observacionais e o papel da anonimização, fazendo propostas que os compatibilizam com a promoção da ciência.

\section{Principais argumentos jurídicos contra $\circ \mathrm{Cl}$}

As CES têm poucos recursos e alguma pulsão jurídico burocrática. É por estas imperfeições que surgem propostas que menorizam as CES e a proteção ética preventiva do participante.

Finda a necessidade de submissão prévia à Comissão Nacional de Proteção de Dados (CNPD), pode querer interpretar-se o RGPD como legitimando que se torneiem normas éticas, por exemplo se o investigador alegar que obter $\mathrm{Cl}$ é um 'esforço desproporcional'.

Desproporcional para quem? Não para o Hospital que declara ser um CESC. Esse contacta os doentes com facilidade para confirmar consultas ou obter pagamentos.

Esta tentação contradiria quer o artigo $9^{\circ}$, número 4 , do RGPD (e considerando 53) que explicita que os países podem manter outros normativos legais que reforcem a proteção dos titulares dos DPS (p.e. a LIC), quer as orientações europeias que priorizam a ética de cada disciplina

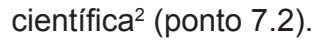

A Acta Médica Portuguesa publicou um artigo ${ }^{3}$ que entende os DPS como informação administrativa na posse do Estado, defendendo o abandono de duas proteções clássicas dos participantes em estudo: o $\mathrm{Cl}$ e a anonimização, validados pela CES. Acrescenta uma proteção (Aceitação de Termos) cujo valor é escasso e contradito pelos seus proponentes quando defendem que a proteção contra a intrusão informática é um mito. Apresenta como pressuposto a Lei $n^{\circ}$ 26/2016 de 22 de agosto, sobre a reutilização de informações administrativas. Essa lei, contudo, dá primazia à proteção dos DPS sobre a reutilização, transpondo duas diretivas Europeias, interessando aqui a Diretiva 2013/37/ UE que exclui a sua aplicação a dados protegidos, como os DPS, nunca nela aparecendo a palavra 'saúde'. As orientações para a interpretação do RGPD também contrariam esta visão, priorizando a ética de cada ciência. Não duvidemos que o que se entender legítimo para os DPS pretéritos, far-se-á com os DPS futuros.

\section{O debate sobre a anonimização}

A lei permite outra solução: anonimizarem-se os DPS. A anonimização é exequível, com a exceção de dados 'únicos' (p.e. genéticos), ${ }^{4}$ ou quando incluem vários quási-identificadores ${ }^{5}$ cruzáveis com grandes bases digitais públicas, como acontece nos EUA.
O RGPD (considerando 26) considera anónimos (anonimizados) os dados que com segurança razoável não são passíveis de serem titularizados, "tendo em consideração a tecnologia atual, a evolução tecnológica, o custo e o tempo que seria necessário despender para conseguir a titularização". O par anonimização / não pedir consentimento protege mais o participante em estudo observacional que o par pseudoanonimização / pedir consentimento.

A anonimização exige perícia, mas gera anonimato. Já a pseudoanonimização e a sua variante 'desidentificação' permitem a reidentificação intencional legítima através de chave. Devem tomar-se medidas para dificultar a reidentificação ilegítima. Para isso existe, no limite, a anonimização irreversível (redundância datada) tendo o defeito de, geralmente, impedir que se audite a veracidade e integridade dos dados ou que o participante beneficie da continuação duma intervenção eficaz. Alguns métodos radicais de anonimização, destinados à libertação pública de dados, têm o defeito de produzir uma perda de precisão dos próprios dados, como acontece na k-anonymization que impede que qualquer combinação de dados seja 'única', substituindo dados discretos por classes de dados. Por exemplo em vez da idade em anos (54 anos), usa classes de idades (50 - 59 anos). ${ }^{6}$

\section{Proposta duma solução ética}

As CES são parcas em recursos e, demasiadas vezes, são o rosto da LIC, uma lei que descura a intervenção com risco negligenciável, a relação médico doente, a mais-valia direta da investigação e é omissa quanto aos estudos emergentes, com participantes transitoriamente incapazes.

Há investigadores que contornam as CES por economia de tempo, empobrecendo os seus estudos e mantendo bases de dados no computador pessoal.

Proponho uma solução que passa pela reinterpretação do CESC, como uma entidade orgânica substantiva e pró-ativa que acrescente competências e capture recursos, focando-se em promover a investigação, nomeadamente investindo no encurtamento dos tempos de resposta da CES.

A formação sobre a proteção de dados é outro exemplo do que um CESC pode oferecer, certificando que o investigador está em condições de anonimizar os dados ou anonimizando-os o CESC. A contratualização externa dessas funções corresponderia a maior exposição dos DPS, e a CES continua obrigada a validar a proteção dos DPS (tal como acontece com o Encarregado de Proteção de Dados no caso de DPS não anonimizados).

Até lá, tenho avançado a seguinte perspetiva:

A CES pode, excecionalmente, prescindir de $\mathrm{Cl}$ nos estudos sem intervenção e a LIC não define a excecionalidade como raridade ou os estudos observacionais teriam de ter seguro, também só excecionalmente prescindível. Excecionalidade significa 'com ressalva' de subtipos específicos de estudos, permitindo a sua 'exclusão' da regra geral, como é o caso da inviabilidade da obtenção de $\mathrm{Cl}$, em estudos relevantes. A CNPD ${ }^{7}$ enfatizou o interesse público de 
um estudo, avaliado pela CES, quando prescinde de $\mathrm{Cl}$, e o Regulamento 707/2016 permite-o quando o investigador é médico do doente. ${ }^{8}$

Defendo a anonimização, se adequada, ou a dispensa do $\mathrm{Cl}$ num estudo se se observar concomitantemente uma combinação razoável de:

1. Inexistência de risco ético major.

2. A sua obtenção é desproporcionalmente difícil ou impossível.

3. $\mathrm{O} \mathrm{Cl}$ introduz um viés.

4. O Cl viola o privilégio terapêutico.

5. O estudo é verdadeiramente retrospetivo.

6. O investigador pertence à equipa assistente do doente.

7. Não envolve dados identificadores.

8. Há proteção credível dos DPS comuns.

9. A investigação tem interesse público direto.

10. O CESC tenta contactar os doentes, exceto se verificar o ponto 6 , podendo aí fazer publicitação simples do estudo, dando uma oportunidade de oposição ao doente.

Se prospetivo, acrescento:

1. O investigador deve obter $\mathrm{Cl}$ logo que possível.

2. O interesse público da investigação foca-se no grupo de que o doente faz parte.

3. A patologia em estudo é a causa do impedimento na obtenção de $\mathrm{Cl}$ prévio (p.e. coma).

Aos investigadores externos não se aplica o Regulamento $707 / 2016$ de 21 de julho, ${ }^{8}$ devendo exigir-se que a colheita de dados seja feita por um membro da equipa médica do doente ou, alternativamente, que o CESC informe diretamente os titulares.

\section{CONCLUSÃO}

A transformação digital dá aos estudos com DPS impacto ético crescente.

Os doentes confiar-nos-ão mais facilmente DPS se não os tomarmos como património a priori nosso, desprezando a sua Autonomia ao não Ihes dar sequer uma possibilidade de oposição à sua participação, presumindo a Confidencialidade como uma batalha perdida no mundo digitalizado e sacrificando o Primado da Pessoa Humana do doente que recorre ao Serviço Nacional de Saúde a bem da ciência.

Defendemos os estudos com DPS anonimizados, que deixaram de ser 'propriedade' do ex-titular, dispensando $\mathrm{Cl}$, ou, se a anonimização for indesejável, que então se respeitem as condições acima descritas compatíveis com os princípios da filosofia moral e a lei, promovendo a ética e as CES.

As propostas clarificam critérios e permitem CES equitativas e menor tempo de resposta - desiderato que incrementará a taxa de adesão dos investigadores ao processo ético.

\section{AGRADECIMENTOS}

Agradeço a Rosalvo Almeida e a António Faria Vaz o incentivo para publicar o presente artigo na Acta Médica Portuguesa.

\section{REFERÊNCIAS}

1. Shuster E. Fifty years later: the significance of the Nuremberg code. N Engl J Med. 1997;337:1436-40.

2. European Data Protection Board. European Data Protection Board endorsement of GDPR WP29. Guidelines on consent. [consultado 2018 set 10]. Disponível em: https://ec.europa.eu/newsroom/article29/itemdetail.cfm?item id $=623051$.

3. Guimarães $R$, Rodrigues $P$, Santos $A$, Dinis-Oliveira RJ. Reutilização de registos clínicos para investigação científica. Acta Med Port. 2018;31:299-302

4. Gymrek M, McGuire AL, Golan D, Halperin E, Erlich Y. Identifying personal genomes by surname inference. Science. 2013;339:321-4.
5. Sweeney L. Uniqueness of simple demographics in the U.S. population. Laboratory for Int'I Data Privacy's Working Paper. 2000; LIDAP-WP4.

6. Samarati $P$, Sweeney $L$. Protecting privacy when disclosing information: k-anonymity and its enforcement through generalization and suppression. Technical Report Computer Science Lab. 1998. [consultado $2018 \mathrm{dez}$ 14.]. Disponível em: www.csl.sri.com/papers/sritr-98-04.

7. Comissão Nacional de Proteção de Dados. Deliberação n 1704/2015. [acedido 2018 set 6]. Disponível em: https://www.cnpd.pt/bin/ orientacoes/DEL_2015_InvestClinica.pdf.

8. Ordem dos Médicos. Código Deontológico (Regulamento 707/2016) Artigo 42. In Diário da República n. ${ }^{0}$ 139/2016, Série II de 2016-07-21. 